Labovitz School of Business \& Economics, University of Minnesota Duluth, 11 E. Superior Street, Suite 210, Duluth, MN 55802

\title{
Rating With Confidence: How Rating Scales Affect Future Wom Behavior
}

David Godes, University of Maryland, USA

Yu-Jen Chen, Lingnan University, Hong Kong

Rating scale adopted by firms affects raters' likelihood of sending subsequent word-of-mouth. We show that subsequent WOM intentions are higher when participants evaluate on a 5-point scale than on a 2-point one. We propose a new construct - "rating certainty" - which reflects raters' certainty belief regarding the score, to explain this.

[to cite]:

David Godes and Yu-Jen Chen (2014), "Rating With Confidence: How Rating Scales Affect Future Wom Behavior", in NA Advances in Consumer Research Volume 42, eds. June Cotte and Stacy Wood, Duluth, MN : Association for Consumer Research, Pages: 430-431.

[url]:

http://www.acrwebsite.org/volumes/1017952/volumes/v42/NA-42

\section{[copyright notice]:}

This work is copyrighted by The Association for Consumer Research. For permission to copy or use this work in whole or in part, please contact the Copyright Clearance Center at http://www.copyright.com/. 


\title{
Rating with Confidence: How Rating Scales Affect Future WOM Behavior
}

\author{
Yu-Jen Chen, Lingnan University, China \\ David Godes, University of Maryland, USA
}

\section{EXTENDED ABSTRACT}

It is fairly well accepted that WOM impact the receivers of social information, however there has been far less research to understand its effect on the information providers. How might the process of providing a product rating affect one's subsequent behavior? For example, will product reviewers behave differently if they offer their rating score on a 2 -pt vs. on a 5 -pt rating scale?

We propose that rating scale can affect senders' future WOM behavior as different scales may influence how certain they feel on the ratings score they assign. For example, given a satisfactory consumption experience, consumer may feel confidence to rate the product as 4 on a 5-point scale, but feel less confident to rate it as 12 on a 15-point scale. Such a belief about one's rating process, which we refer to "rating certainty", is defined to reflect raters' certainty belief regarding the score. As the rating certainty level is higher, it implies that their evaluation is more likely to be valid, therefore is more predictable on their evaluation-consistent behavior, such as future WOM.

Any belief or thought can be held with subjective levels of confidence (Berger and Mitchell 1989). When a belief is about one's own personality or traits, the certainty belief refers to self-certainty (Clarkson et. al 2009). When a belief object is one's attitude, the certainty belief refers to attitude certainty. While belief is a first-order cognition, certainty judgment is considered a second-order cognition (or metacognition) that is attached to the first-order cognition and reflects thoughts about one's own thoughts or thought process (Jost, Kruglanski, and Nelson 1998). Analogously, when rating a product rating task and offering a rating score (first-order cognition), a second-order cognition is expected to occur. We refer to this secondorder cognition as rating certainty, which reflects the extent to which a rater subjectively believes that the provided rating score can precisely capture her underling utility. Since rating certainty is a type of certainty belief, it is expected to follow similar properties as other constructs in this class. In particular, a belief with higher certainty is more likely to predict belief-associated behavior (Fazio and Zanna 1978). Therefore, when raters are more certain that the assigned rating score is accurate, they are more likely to engage in behavior that is consistent with the rating- in this context, WOM communication.

One factor that may affect one's rating certainty level may be the choice of rating scale. For instance, Komorita and Graham (1965) suggest that a scale with fewer scale points may not provide sufficient discrimination by consumers, however a scale with too many scale points may go beyond consumers' ability to discriminate one point from the other. This suggests that one's rating certainty level may be affected by the number of scale points: a rater may be less certain about her rating when the scale design is not capable of reflecting her true underlying utility. In order to examine whether scale points can affect rating certainty, we choose two of the most commonly used scale formats, 2-point (as in "thumbs up" and "thumbs down" or "helpful" and "not helpful," etc.) and 5-point scales. We predict that a 2-point scale may not fully capture one's product evaluation, compared to a 5-point scale, because of its limited discrimination and meaningfulness (Viswanathan, Sudman, and Johnson 2004)). We conducted three studies to examine our hypotheses.

Study 1 aims to examine whether different product rating scales can affect rating certainty and, in turn, WOM intention. Given that rating certainty is close to attitude certainty, an important and valid concern is the extent to which we are able to distinguish between these constructs. This represents an important secondary goal of the study. We conducted a 2 (rating scale: $2-p t, 5-p t) \times 2$ (counterbalancing order: attitude certainty before rating certainty or vice versa) between-subjects design. One-hundred twenty two Mturk participants were recruited and were randomly assigned to treatments. They first watched a two-minute video. Then, depending on their conditions, about half of the participants first rated the video, assessed their rating certainty, and then reported attitude certainty. The other half first reported attitude certainty, and then rated the video and provided rating certainty.

Rating score with two different scales (2-pt, 5-pt), which had the same end-point anchors: "awful" and "excellent." Rating certainty was captured by four questions $(\alpha=.95)$ : ("How sure are you that the rating score $[\mathrm{x}]$ you assigned is precise?", "How definite is your rating score $[\mathrm{x}]$ of the video? "The rating score $[\mathrm{x}]$ I assigned was clear", and "The rating score $[\mathrm{x}] \mathrm{I}$ assigned was precise, from "disagree" to "agree").Next, we measured attitude certainty via two items ("How certain [sure] are you of your opinions toward the video?";r=.94). WOM intention was captured by three seven-point questions ("I am likely to tell my friends about this video in the next week/ to forward this video at least to one person in the next week/ to share the video on any social network such as Facebook or Twitter in the next week; 1= "strongly disagree," and 7 = "strongly agree"). We average the three items to formulate one WOM intention index $(\alpha=.96)$. As predicted, rating certainty significantly predicted WOM intention in a regression model $(\beta=0.24, \mathrm{t}(119)=3.83, p<.001)$. In addition, we found that participants in the 5-point scale showed higher rating certainty level $\left(\mathrm{M}_{5}=7.64\right)$ than those in the 2-pt condition $\left(\mathrm{M}_{2}=6.41 ; \mathrm{F}(1,119)=10.10, p<.01\right)$. A mediation analysis further confirmed that rating certainty drove the impact of scale on WOM. Attitude certainty, on the other hand, was not affected by scale condition.

Study 2 aimed to replicate study 1 and to examine an alternative explanation that self-efficacy (Wood and Bandura 1989), rather that rating certainty, drives the effect. Sixty-one Mturksy were randomly assigned to either a 2-pt scale condition or a 5-pt scale condition. The study procedure was similar to study 1 , except we employed a different video and collected general self-efficacy measures using 10 items (Schwarzer and Jerusalem 1995). Similar to study 1, a regression model revealed a positive relationship between rating certainty and $\operatorname{WOM}(\beta=0.31, \mathrm{t}=3.22, p<.01)$. Also, participants in the 5-point scale showed higher rating certainty level $\left(\mathrm{M}_{5}=7.63\right)$ than those in the 2-pt condition $\left(\mathrm{M}_{2}=6.20 ; \mathrm{F}(1,57)=16.27, p<.001\right)$. However, self-efficacy level was not affected by scale condition $\left(\mathrm{M}_{2}=7.85 ; \mathrm{M}_{5}=7.90\right)$.

Study 3 attempted to make rating certainty less salient to raters by removing the measure. We measured WOM decision immediately after participants reported their evaluation on either a 2-pt or 5-pt rating scale. Consistent with the first two studies, while $32.4 \%$ of the participants under 5-pt condition decided to share the video, only $18.6 \%$ of those under 2 -pt condition chose to share $(\beta=-.88$, $\left.\chi^{2}(1)=4.70, p=.03\right)$. These results were further evidence that rating scale could affect WOM likelihood, even when rating certainty was not made salient.

Taken together, this research propose a new construct, rating certainty, and show that it mediates this impact of rating scale on WOM. We not only demonstrate a novel and exciting phenomenon, but also highlight the importance of rating certainty in driving WOM behavior. 


\section{REFERENCES}

Baggozi. Richard P., Youjae Yi, and Lynn W. Phillips (1991), "Assessing Construct Validity in Organizational Research," Administrative Science Quarterly, 36 (3), 421- 458.

Bandura, Albert (1977), "Self-efficacy: Toward a Unifying Theory of Behavioral Change," Psychological Review, 84 (2), 191-215.

Berger, Ida E. and Andrew A. Mitchell (1989), "The Effect of Advertising on Attitude Accessibility, Attitude Confidence, and the Attitude-Behavior Relationship," Journal of Consumer Research, 16 (December), 269-279.

Berger, Jonah and Raghuram Iyengar (2013), "Communication Channels and Word of Mouth: How the Medium Shapes the Message," Journal of Consumer Research, 40 (October), 567579.

Berger, Jonah and Eric M. Schwarz (2011), "What Gets Talked About? Drivers of Immediate and Ongoing Word-of-Mouth," Journal of Marketing Research, 48 (October), 869-880.

Clarkson, Joshua J., Zakary L. Tormala, Victoria L. DeSensi, and S. Christian Wheeler (2009), "Does Attitude Certainty Beget Self-Certainty?" Journal of Experimental Social Psychology, 45, 436-439.

Cox, Eli P. (1980), "The Optimal Number of Response Alternatives for a Scale: A Review," Journal of Marketing Research, 17 (November), 407-422.

Cronbach, Lee J. (1950), "Further Evidence on Response Sets and Test Design," Educational and Psychological Measurement, 10 (Spring), 3-31.

DeMarree, Kenneth G., Richard E. Petty, and Pablo Brinol (2007), "Self-certainty: Parallels to Attitude Certainty," International Journal of Psychology and Psychological Therapy, 7 (2), 159-188.

Dichter, Ernest (1966), "How Word-of-Mouth Advertising Works," Harvard Business Review, 44 (Nov-Dec), 147-166.

Fazio, Russell H. and Mark P. Zanna (1978), "On the Predictive Validity of Attitudes: The Roles of Direct Experience and Confidence, “ Journal of Personality, 46 (2), 228-243.

Grice, H. Paul (1975). "Logic and Conversation," in Syntax and semantics 3: Speech arts, Cole, Peter and Jerry L. Morgan eds. New York: Academic Press, 41-58.

Hayes, Andrew F. (2012), PROCESS: A versatile computational tool for observed variable mediation, moderation, and conditional process modeling" [White paper]. Retrieved from http://www.afhayes.com/public/process2012.pdf.
Jost, John, Arie W. Kruglanski, and Thomas O. Nelson (1998), "Social metacognition: An expansionist review," Personality and Social Psychology Review, 2, 137-154.

Komorita, S. S. and William K. Graham (1965), “"Number of Scale Points and the Reliability of Scales," Educational and Psychological Measurement, 25 (November), 987-995.

Moore, Sarah G. (2012), "Some Things Are Better Left Unsaid: How Word of Mouth Influences the Storyteller," Journal of Consumer Research, 38 (April), 1140-1154.

Muñiz, Albert M. Jr. and Thomas C. O'Guinn (2001), "Brand Community," Journal of Consumer Research, 27 (March), 412-432.

Schwarz, Norbert, Hans-J. Hippler, Brigitte Deutsch, and Fritz Strack (1985), "Response Scales: Effects of Category Range on Reported Behavior and Comparative Judgments,"Public Opinion Quarterly, 49 (Fall), 388-395.

Schwarzer, Ralf and Matthias Jerusalem (1995), "Generalized SelfEfficacy Scale," in Measures in Health Psychology: A User's Portfolio. Causal and Control Beliefs, J. Weinman, S. Wright, and M. Johnston, Windsor, UK: NFER-NELSON, 35-37.

Tormala, Zackary L. and Derek D. Rucker (2007), “Attitude Certainty: A Review of Past Findings and Emerging Perspectives, "Social and Personality Psychology Compass, 1 (November), 469-492.

Tourangeau, Roger, Lance J. Rips, and Kenneth Rasinski (2000), The psychology of survey response. NY: Cambridge University Press.

Ryu, Gangseog and Lawrence Feick (2007), “A Penny for Your Thoughts: Referral Reward Programs and Referral Likelihood," Journal of Marketing, 71 (January), 84-94.

Viswanathan, Madhubalan, Seymour Sudman, and Michael Johnson (2004), "Maximum versus meaningful discrimination in scale response: Implications for validity of measurement of consumer perceptions about products," Journal of Business Research, 57, 108-124.

Widaman, Keith F. (1985), "Hierarchically Nested Covariance Structure Models for Multitrait-Multimethod Data," Applied Psychological Measurement, 19, 1-26.

Wood, Robert and Albert Bandura (1989), "Impact of Conceptions of Ability on Self-Regulatory Mechanisms and Complex Decision Making, Journal of Personality and Social Psychology, 56 (3), 407-415. 